\title{
Cadmium lung adsorption, citrullination and an enhanced risk of COPD
}

\author{
To the Editor:
}

The paper "Cadmium in tobacco smokers: a neglected link to lung disease?" by Ganguly et al. [1] was read with great interest. The authors excellently review the evidence that cadmium (Cd) present in cigarette smoke is associated with chronic obstructive pulmonary disease (COPD) development. They emphasise the importance of lung Cd tissue levels by highlighting a study that demonstrated significantly increased lung tissue levels of $\mathrm{Cd}$ in severe COPD lung tissue compared to smokers without COPD, although the consumption of tobacco was higher in those patients with severe COPD [2]. Furthermore, GANGULY et al. [1] cite further evidence linking Cd exposure to COPD development, such as development of emphysema in animal models exposed to nebulised $\mathrm{Cd}$ and in individuals exposed to occupational $\mathrm{Cd}$ fumes. Additionally they emphasise the accumulation of $\mathrm{Cd}$ in smokers' organs, such as the kidney, compared to nonsmokers, and that Cd statistically increases markers of innate immunity activation.

Given the above, why has Cd been neglected as an important trigger for COPD development in smokers? After all, ElLis et al. [3] found that Cd accumulates in the liver and kidney in direct proportion to pack-years smoked. Interestingly, they also demonstrated that blood and urinary Cd levels did not correlate with $\mathrm{Cd}$ levels in liver and kidney tissues, suggesting that traditional ways of measuring $\mathrm{Cd}$ exposure do not always reflect organ-specific tissue levels [3]. The lung is a case in point: it is most likely that $\mathrm{Cd}$ acts locally in the lung and acts intracellularly to induce COPD; therefore, lung retention and Cd entry into cells are likely to be crucial to this process. Almost all the studies investigating Cd and COPD development have measured blood, bronchoalveolar lavage fluid or urine levels and not lung tissue levels (reviewed in [1]); therefore, the important association between Cd exposure and COPD has been missed.

In addition to lung retention, $\mathrm{Cd}$ can either be exhaled or absorbed into the smoker's circulation. Therefore, Cd blood or urinary levels will not capture those at greatest potential risk of COPD development as a consequence of enhanced lung retention. It has been suggested that inhaled occupational dusts (wood, silica, coal, kaolin, clay earth and textile) and fumes (bitumen tar) known to increase the risk of COPD act as potent adsorbers of Cd derived from cigarette smoke, by trapping Cd in the lung [4].

Therefore, those most at risk of COPD are working-class smokers exposed to occupational vapours, gases, dusts and fumes, undertaking jobs not necessarily associated with $\mathrm{Cd}$ exposure per se, but rather with $\mathrm{Cd}$ adsorption [5]. Emphasising the importance of lung Cd tissue levels to emphysema development, a study demonstrated that tissues (kidney, lung and liver) from patients with severe emphysema have significantly greater $\mathrm{Cd}$ concentrations compared to age-matched control subjects, and furthermore that the greatest differences were in lung Cd concentrations [6].

An important epidemiological study from the third US National Health and Nutrition Examination Survey (NHANES) demonstrated a significant association between lower forced expiratory volume in $1 \mathrm{~s}$ (FEV1) and raised serum Cd levels in both current and former smokers [7]. This was not observed in never-smokers. However, lower FEV1 can be caused by a plethora of lung diseases, whereas Cd exposure appears to associate specifically with emphysema in accidental occupational exposures (reviewed in [1]). Accordingly, as emphysema is very rare in never-smokers as opposed to smokers, it follows that individuals with lower FEV1 have a far lower prevalence of emphysema if they have never smoked, compared to smokers with a diminished FEV1, and therefore there is no appreciable association of emphysema with Cd exposure.

@ERSpublications

Cadmium in cigarettes has been overlooked as a risk factor for COPD development as studies have failed to take into account lung tissue levels. The levels of cadmium in blood and urine may not reflect lung cadmium tissue levels in smokers. http://ow.ly/u6Of30lCyw8

Cite this article as: Hutchinson D. Cadmium lung adsorption, citrullination and an enhanced risk of COPD. Eur Respir Rev 2018; 27: 180054 [https://doi.org/10.1183/16000617.0054-2018]. 
An editorial about the NHANES study, by HENDRICK [8], makes the reasonable point that emphysema induced by occupational Cd fume exposure as described by DAvison et al. [9] cannot be compared to emphysema induced by cigarette smoke, because of the marked difference observed in Cd exposure between those men with emphysema exposed to occupational fumes alone compared to men with emphysema exposed to cigarette smoke alone. Hendrick [8] implied that $\mathrm{Cd}$ in large doses relevant to industrial exposures can induce emphysema, but the doses relevant to cigarette smoking are too small to induce disease and that, by inference, smoking induces emphysema via a Cd-independent mechanism. Further analysis of the study by DAvison et al. [9] casts doubt on Hendrick's assertion.

DAvison et al. [9] studied a cohort of men who worked manufacturing copper-Cd alloy. The exposed men $(\mathrm{n}=75)$ worked close to the furnaces and had appreciable liver concentrations of $\mathrm{Cd}$ as measured in vivo by neutron activation analysis $(26.1 \mathrm{ppm})$ compared to workers $(n=68)$ in the same factory working distantly from the furnaces who had levels of $0.6 \mathrm{ppm}$, a 44 -fold difference in exposure. Crucially, the only tissue levels of $\mathrm{Cd}$ measured were from liver.

Chest radiography revealed emphysema in 14 (19\%) out of 75 of the exposed men and five (7\%) out of 68 of the unexposed men. Of the 75 exposed men, 12 had never smoked and two (17\%) out of 12 developed radiological emphysema. Of the exposed men who smoked, 12 (19\%) out of 63 developed radiological emphysema. In the unexposed never-smokers, zero out of 14 developed radiological emphysema, compared to five (9\%) out of 54 unexposed smokers. Taken together, these important findings demonstrate that $\mathrm{Cd}$ exposure clearly increases the risk of emphysema. Furthermore, there does not appear to be an additive effect of industrial $\mathrm{Cd}$ exposure and smoking as the rate of emphysema in exposed never-smokers was similar to exposed smokers (17\% versus 19\%). These data do not suggest any interaction between smoking and occupational Cd inhalation and emphysema development.

To make sense of these data, one needs to consider that the delivery of $\mathrm{Cd}$ is different between the $\mathrm{Cd}$ furnace fume-exposed men and unexposed smokers. In the furnace fume-exposed men, the Cd would be present as $\mathrm{Cd}$ oxide $(\mathrm{CdO})$, resulting in very high levels in the lung and systemic circulation as a consequence of pulmonary absorption, hence the findings of an increased risk of both emphysema and greatly raised liver levels. The lung levels are likely to have been so appreciably raised in these men that the addition of $\mathrm{Cd}$ derived from cigarette smoke is unlikely to have added any meaningful risk of emphysema. This is clearly demonstrated in the similar prevalence of emphysema in exposed smokers and never-smokers. Interestingly, despite very high levels of Cd exposure in the furnace workers, the prevalence of emphysema is $\sim 20 \%$, suggesting that some individuals are much more prone to Cd-related emphysema development than others.

In contrast, in the unexposed smokers, $\mathrm{Cd}$ is delivered to the lung as $\mathrm{CdO}$ in the gaseous phase and $\mathrm{Cd}$ chloride $\left(\mathrm{CdCl}_{2}\right)$ in the particulate phase of cigarette smoke, adsorbed by cigarette tar [10]; therefore, Cd within the tar is likely to be retained in the lung rather than absorbed into the systemic circulation. This may explain the relatively high prevalence of emphysema in unexposed smokers (9\%), despite liver Cd levels of 44-fold lower than exposed smokers. Therefore, despite relatively low liver Cd concentrations, unexposed smokers may conceivably have had disproportionately high lung levels as previously described [6].

Recently, it has been demonstrated that Cd induces intracellular citrullination in lung epithelial cells, with $\mathrm{CdCl}_{2}$ having a greater effect than $\mathrm{CdO}$ [11]. Intracellular citrullination is pivotal to the development of the autoimmune disease rheumatoid arthritis and a study has also observed citrullination of vimentin in COPD lung samples of both smokers and nonsmokers [12]. Some time ago it was suggested that COPD may be an autoimmune disease [13] and Cd exposure with subsequent lung citrullination may well be the missing link.

David Hutchinson

Dept of Rheumatology, Royal Cornwall Hospital Trust, Truro, UK.

Correspondence: David Hutchinson, Dept of Rheumatology, Royal Cornwall Hospital Trust, Truro, Cornwall, TR1 3LQ, UK. E-mail: david.hutchinson5@nhs.net

Provenance: Submitted article, peer reviewed.

Received: June 112018 | Accepted after revision: Aug 162018

Conflict of interest: None declared.

Support statement: Funding for D. Hutchinson's research is received from the Cornwall Arthritis Trust. No research money has been received from the tobacco industry. 


\section{References}

1 Ganguly K, Levänen B, Palmberg L, et al. Cadmium in tobacco smokers: a neglected link to lung disease? Eur Respir Rev 2018; 27: 170122.

2 Hassan F, Xu X, Nuovo G, et al. Accumulation of metals in GOLD4 COPD lungs is associated with decreased CFTR levels. Respir Res 2014; 15: 69.

3 Ellis KJ, Vartsky D, Zanzi I, et al. Cadmium: in vivo measurement in smokers and nonsmokers. Science 1979; 205: 323-325.

4 Murphy D, Bellis K, Hutchinson D. Occupational dust and cigarette smoke exposure might link rheumatoid arthritis to COPD. Lancet Respir Med 2018; 6: e36.

5 Blanc PD, Iribarren C, Trupin L, et al. Occupational exposures and the risk of COPD: dusty trades revisited. Thorax 2009; 64: 6-12

6 Hirst RN Jr, Perry HM Jr, Cruz MG, et al. Elevated cadmium concentration in emphysematous lungs. Am Rev Respir Dis 1973; 108: 30-39.

7 Mannino DM, Holguin F, Greves HM, et al. Urinary cadmium levels predict lower lung function in current and former smokers: data from the Third National Health and Nutrition Examination Survey. Thorax 2004; 59: $194-198$

8 Hendrick DJ. Smoking, cadmium, and emphysema. Thorax 2004; 59: 184-185.

9 Davison AG, Fayers PM, Taylor AJ, et al. Cadmium fume inhalation and emphysema. Lancet 1988; 1: 663-667.

10 Piadé JJ, Jaccard G, Dolka C, et al. Differences in cadmium transfer from tobacco to cigarette smoke, compared to arsenic or lead. Toxicol Rep 2015; 2: 12-26.

11 Hutchinson D, Müller J, McCarthy JE, et al. Cadmium nanoparticles citrullinate cytokeratins within lung epithelial cells: cadmium as a potential cause of citrullination in chronic obstructive pulmonary disease. Int $J$ Chron Obstruct Pulmon Dis 2018; 13: 441-449.

12 Lugli EB, Correia RE, Fischer R, et al. Expression of citrulline and homocitrulline residues in the lungs of non-smokers and smokers: implications for autoimmunity in rheumatoid arthritis. Arthritis Res Ther 2015 ; 17 : 9.

13 Agusti A, MacNee W, Donaldson K, et al. Hypothesis: does COPD have an autoimmune component? Thorax 2003; 58: 832-834. 